\title{
DECEPTION AND MUTUAL TRUST: A REPLY TO STRUDLER ${ }^{1}$
}

\author{
J. Gregory Dees and Peter C. Cramton
}

\begin{abstract}
Alan Strudler has written a stimulating and provocative article about deception in negotiation. He presents his views, in part, in con trast with our earlier work on the Mutual Trust Perspective. We believe that Strudler is wrong in his account of the ethics of deception in negotiation and in his quick dismissal of the Mutual Trust Perspective. Though his mistakes may be informative, his views are potentially harmful to business practice. In this paper, we present arguments against Strudler's position and attempt to salvage the Mutual-Trust Perspective from his attack. Strudler's work reaffirms the need for a more pragmatic approach to business ethics. We close the paper with a renewed call for more constructive and practical approaches to business ethics research.
\end{abstract}

$D^{\mathrm{s}}$ eception in negotiation has long been an intriguing topic for business ethicists. Strudler has added to the intrigue by proposing what for many ethicists will seem to be a counter-intuitive view: that some forms of deception in business negotiation are morally neutral or even benign. Strudler's approach is not simply a reaffirmation of Albert Carr's thesis (1968) that business has its own ethics. Rather, Strudler offers a novel analysis of negotiation tactics.

In presenting his views, Strudler follows a time-honored tradition of an author preparing readers for his own views by first purporting to uncover fatal flaws in alternative theories. Since the reader does not have the earlier work freshly in mind or readily at hand, the author's characterization of the earlier theory is decisive. Readers end up believing that anyone with an ounce of moral decency could not have seriously put forward the earlier theory and conclude any new theory would be an improvement. Having lowered the bar, the author, in this case Strudler, jumps over it with apparent ease.

Since we have the distinction of being Strudler's first victims, we have taken a special interest in his paper. Strudler casts our 'Mutual Trust Perspective" (sees and Cramton, 1991) as a kind of Dr. Jeckyll/Mr. Hyde theory. On one hand, he portrays us as uptight prudes who cluck moral disapproval over something as trivial as the deceptions engaged in by a Madrid taxi driver hoping to extract an extra commission for carrying heavy boxes. On the dark side, Strudler describes us as wild-men who would cheer-on violent, paranoid software entrepreneurs looking to beat the living daylights out of one another in order to gain trade secrets. Naturally, we believe that he has got us wrong. We also think that his theory is fatally flawed, even harmful. However, we will resist the temptation to respond with a caricature of Strudler's work. Such a strategy is not likely to be effective in this case since readers of this journal probably have Strudler's views freshly in mind and, if not, could easily check our claims by turning a few pages. The principle of self-defense may justify an unfair counter-attack, but the context prohibits it.

Strudler was not the first to raise questions about our work (see Boatright 1992, Gibson 1994), but he is the most aggressive in his critique. We are flattered by the attention, but disappointed that our arguments have not been universally compelling. While the critical response has convinced us that we need to be clearer about our claims and that we could improve on our earlier work, our central convictions remain unshaken. In response to Strudler's paper, we will explain why deception is a morally regrettable feature of business negotiations, and why the Mutual Trust Perspective is a reasonable working hypothesis.

\section{Deception, Signaling, and Moral Regret}

On one point, Strudler's interpretation of our work is correct. We do object to his contention that deception in negotiation, even deception about one's reservation price, is morally benign and not a cause for regret. Though we do not hold the extreme view he attributes to us, we believe that "outside of a few recreational contexts, deception is a regrettable feature of business negotiations, even when it is justified (or commonplace)" (1993, p. 361). For us, "morally regrettable" has a precise definition: a practice is morally regrettable if the world would be a better place with less of it and a worse place with more. Our thesis is that it would be good if parties to a negotiation reduce deception through some feasible and fair method. Despite Strudler's arguments to the contrary, we believe this is not limited to deception about material facts but also is true for deception about settlement preferences (including reservation prices). We acknowledge settlement preference deception may be hard to prevent, detect, police, or punish; 
nonetheless it is regrettable. Indeed, we fear that Strudler's arguments alleviate the moral pressure to find techniques to increase trust and reduce deception in this area.

Studler's argument for deception fails because it rests on two conflations. The first involves the very notion of deception. Strudler mixes the idea of a deliberate deception intended to mislead with the idea of making false statements in order to signal useful information. As we explicitly defined the term, deception involves "the intention of creating or adding support to a false belief in another party" (1993, p. 362 emphasis added). By contrast, Studler's false statements (which he labels "lies") are meant as a "signaling and symbolic device" (p. 1) to help negotiators reach a mutually beneficial agreement. It is true that among sophisticated negotiators who are skilled at decoding one another's statements what Strudler describes may occur - with little harm being done. But it is hard to count these "lies" as instances of intentional deception, since they are not expected to mislead, and in fact do not mislead. The power of Strudler's argument and examples rests on blurring this distinction.

Even though false statements that signal useful information may be used to strike mutually beneficial bargains, making such statements can hardly be counted as a socially desirable practice. In these negotiations, the signals are usually noisy at best, decoding is more of an art than a science, and conveying the truth even when you desperately want to can be very difficult. Verbal fencing between skilled business negotiators may lead to inefficiencies. Contexts in which the decoding scheme is so precise and the negotiation so well-choreographed as to avoid these problems are rare indeed. Think of the challenges in decoding inflated letters of recommendation.

If Strudler means to include deliberate attempts to mislead in his account of deception, it is even more difficult to see how negotiations could be "mutually advantageous." True, negotiations that involve deception sometimes end up in mutually advantageous agreements, but that hardly supports the belief that the deception was in any way instrumental to achieving the result. Strudler fails to demonstrate a causal link between deceptive strategies and the eventual settlement; he seems to believe that the only alternative to his version of negotiations is the failure to reach an agreement.

Strudler underestimates the costs of deception, even when an intentional effort fails to mislead. Current theory and empirical studies show that attempts at deception are costly (see Kennan and Wilson, 1993). Private information about settlement preferences creates incentives for deception, which leads to inefficiencies. Negotiators often take costly actions in order to convince rivals of the truth. For example, a firm may endure a costly strike in order to convince workers that it is unable to pay a high wage. Deceptive activities generally lead to increased bargaining costs, increased post-agreement monitoring costs, and missed opportunities for those mutually advantageous agreements that Strudler prizes so highly. How many people have walked away from potentially mutually advantageous deals either because of frustration with the negotiating process, or because they came to believe (falsely) that no agreement was possible?

Furthermore, Strudler never fully envisions the fallout from successful deception. Successful deceptions often involve gaining a person's trust during the negotiation process only to abuse it; the deception is, in essence, a broken promise. When both parties are trying to do the same thing to one another, we may not cry too much for the loser, especially if they are equally skilled. Nonetheless, we may still find the nature of the process to be unfortunate, even offensive.

Strudler might counter that deception often allows both parties to leave the negotiation believing they got a good deal, even when they did not by any objective standards. On this point, Howard Raiffa (1982) counsels that it is not a good idea to reveal one's reservation price after a deal has been struck. While Strudler cites Raiffa's statement as support of his view, it may simply be sound advice for avoiding further confrontation. Telling someone that they have been duped is not honesty, it is a taunt. Anyone who has supervised negotiation exercises has seen the indignation and outrage expressed by students who have agreed to settlements far above their opponent's reservation price. Even when these settlements are technically "mutually advantageous," the students' reactions generally contain a judgment of their opponent's tactics that is hardly "morally benign." Raiffa's advice cuts sharply against Strudler, not in his favor. If reservation-price deception were benign, why not reveal? The manipulative character of deception is morally problematic, even when a deceived negotiator leaves feeling good about an unwise agreement. It would be perverse to place a positive moral value on this sort of false consciousness, as pleasant as it may be at the time.

For these reasons, we regard deception about settlement preferences as morally regrettable, even when it may be locally (individually) justified. We may all marvel at the ability of people to make a successful end out of a poor process, but this in no way makes the process less regrettable. Strudler offers no 
compelling invisible-hand type of argument linking attempts at deception to better negotiation outcomes. If he had one, it certainly would be a breakthrough.

Strudler's second conflation involves the notion of moral regret. He fails to make the distinction between 'wrongdoing' on the part of an individual and a practice being 'morally regrettable" from the standpoint of society. As the much analyzed prisoner's dilemma shows, this distinction is crucial since individuals may be held blameless for defecting (i.e. deceiving), even though this course of action is not socially optimal. In his article, Strudler concentrates on whether individual negotiators should be regarded as wrongdoers in order to judge if the behavior is socially desirable or not. For instance, in contrasting his view with ours, Strudler states, "When deception in negotiation makes sense, it is ordinarily not as a way of fending off a prospective attacker or wrongdoer, but instead because of its promise as a mutually beneficial solution to a problem confronted by negotiators who, for morally benign reasons, cannot trust each other" (p. 2). However, neither party need be a wrongdoer for the practice of deception to be regrettable-people can engage in regrettable social practices for "morally benign reasons" from their own standpoint. As we argue below, Strudler's inability to distinguish between levels of analysis also leads to his mischaracterization of the Mutual Trust Principle.

Our primary objection to Strudler is that we believe it is a good thing to reduce deception in negotiation, including settlement issue deception. What most troubles us about his view is that it provides a rationale for business negotiators to neglect the valuable process of building trust and reducing unfortunate wasteful efforts to mislead. In this regard, Strudler functions as an apologist for the status quo. His view justifies a system of commercial transactions that encourages and rewards deceptive skill. Fortunately, the history of economic development seems to show progress on the other side, as practices (money-back guarantees, etc.) and institutions (Better Business Bureaus, etc.) are developed to help reinforce trust. (See Cramton and Dees 1993 for a discussion of practical devices for reducing deception.) These practices and institutions even are beginning to have a bearing on reservation prices. For instance, many appliance stores offer price guarantees, many auto dealers offer no-haggle pricing, and third parties offer information (e.g. the dealer's invoice price on a car) that can help consumers determine a seller's reservation price.

\section{Mutual Trust, Prudence, and Moral Progress}

Strudler acknowledges the importance of trust in understanding deception in negotiation, but he rejects the Mutual Trust Perspective (MTP) we proposed in 1991. No doubt, the MTP could use some clarification, refinement, and improvement, and it will certainly offend some people who would urge unconditional commitment to moral principles However, when it is placed into its proper context, we believe that it still serves its purpose. We proposed the Mutual Trust Perspective (MTP), to capture how people who are neither saints nor scoundrels might justify otherwise questionable conduct in morally ambiguous contexts. The original statement of the central principle went as follows:

Mutual Trust Principle: It is unfair to require an individual to take a significant risk or incur a significant cost out of respect for the interests or moral rights of others, if that individual has no reasonable grounds for trusting that the relevant others will (or would) take the same risk or make the same sacrifice. (p. 144)

At the heart of Strudler's attack on the MTP is an example that purports to demonstrate how the MTP could not be "part of a minimally decent conception of morality" or an appropriate interpretation of business behavior (p. 5). The example involves the case of software entrepreneurs Jones and Smith, the latter "a scurrilous competitor who would do anything, perhaps even physically harm an opponent to get ahead." Strudler then argues that the MTP would justify Jones administering a beating to Smith, or Jones engaging in material misrepresentation (fraud) against Smith, in order to get Smith's trade secrets. Since such behavior is obviously well beyond the bounds of permissible business behavior, Strudler rejects MTP. In the process, he mischaracterizes MTP as a "self-defense" explanation for deception in negotiation. While we do refer to "defensive deception," Strudler's definition of self-defense goes well beyond, placing MTP in the same category as views "expressing the idea that wrongdoers such as murderers or liars, by virtues of their wrongdoing, forfeit or waive some of their rights to be treated as we treat innocent persons" (p. 3).

We find Strudler's attack inventive, but his interpretation of MTP is wildly different from what we originally intended. Both the characterization and the example wrench MTP out of its context and misstate the central thesis of our work. The focus in MTP is as much on the circumstances of the negotiation as on 
the character of the other party. In introducing MTP, we said that the principle "points to a consideration about the specific social context in which actions are taken that can serve, other things being equal, to undermine obligations derived from ideal moral reasoning" (1991, p. 144 emphasis added). The MTP is not concerned with "self-defense," in Strudler's sense. It is not based on any idea of moral wrongdoing by others but simply on the lack of reasonable grounds for trust in a specific social context. It does not presuppose that inherent moral rights are forfeited by anyone, since the absence of trust in these contexts undermines the very notion of rights.

Boatright (1992) made much of the similarity between MTP and Hobbes's "two-level theory that makes allowances for imperfect conditions in which trust is lacking" (p. 70). Like Hobbes, MTP suggests goodwill is conditional, since moral commitment requires a social context in which an individual has reasonable grounds for trusting others before making the same commitment. The principle difference between the MTP and Hobbes is that the MTP envisions trust emerging not in the one fell swoop of a Leviathan, but by incremental and evolutionary efforts to "tame" various domains of human activity. In these domains, trust is built through a variety of imperfect mechanisms and the state of nature is conquered inch by inch. Where the social context has not allowed trust to be built, moral obligations weaken because of the sense of "fair play" expressed in the MTP. Each transaction between individuals takes place in a number of different domains, some "tamed" and others not. Moral obligations in "untamed" domains may be noble, but they are often futile.

To better understand how Strudler's example does an injustice to the MTP, it is best to reconstruct what led us to posit the MTP. We began not with a principle but a puzzle: Why is deception about settlement preferences (reservation prices) condoned, while deception in many other areas is condemned? How do individuals who consider themselves decent and moral justify these deceptive behaviors? As one explanation of this puzzle, we argued that negotiators felt that while some types of deception were indeed "tamed" by social norms, laws, and third-party institutions, for other matters, the negotiators were still in a Hobbesian state of nature, what we termed a "Hobbesian frontier." In particular domains (e.g. reservation prices), people invoked something like the Mutual Trust Principle because of the difficulty in establishing trust for their social context, not because their opposite numbers are bad people who had forfeited their rights. People adopted the MTP because they were unwilling to sacrifice their personal interests to moral principles without grounds for trusting that others would make the same sacrifice.

The MTP does not (and certainly was not intended to) imply that you can do anything to a person that the person might be willing to do to you, if they had the opportunity. In the example Strudler offers, Jones would have called the police, since physical coercion is a "tamed" area-case closed. MTP does not license Jones to resort to physical violence or fraud. These behaviors are not on the Hobbesian frontiers, at least not in our relatively stable society. One might imagine societies less "tame" than ours in which individuals may feel justified in resorting to these more aggressive forms of behavior in certain domains. However in his example, Strudler has not constructed such a context.

Strudler's example fails on other grounds as well. The Mutual Trust Principle specifically states that it is "unfair to require an individual to take a significant risk or incur a significant cost" in the absence of reasonable grounds for trusting the other person. Strudler's examples are weak in showing significant risks and costs to Jones if he refrains from beating or defrauding Smith. Failing to get Smith's trade secret is not a significant "cost" to Jones. Though the line can be hard to draw analytically, gaining a benefit is intuitively different from avoiding a significant cost or risk. As a benchmark, we propose comparing the risks and costs of doing business in similar conditions, but where reasonable grounds for trust are present. The issue is whether the absence of trust in a domain significantly increases the costs and risks associated with unilateral moral restraint. As Strudler defines the case, this sort of incremental risk or costs does not seem to be present. That is, Jones would face a legitimate competitive risk from Smith and his trade secrets, even if Smith were trustworthy.

Strudler may not be the only one to misread MTP in this way. Therefore, we should restate the core principle to include the emphasis on social context that we elaborated in our previous articles:

Revised Mutual Trust Principle: Obligations to refrain from specific kinds of morally regrettable conduct are diminished (perhaps eliminated) for an individual when the following two conditions are present: 1) the individual is operating in a trust-deficient social context, and 2) refraining from the regrettable conduct would cause the individual to bear significant incremental risks or incur significant incremental costs.

A Trust-Deficient Social Context is a domain of human interaction in which participants lack reasonable grounds for trusting relevant others not to engage in morally regrettable conduct. 
Incremental Costs and Risks are those that would not be present if the individual were in a context with grounds for trust and could reasonably rely on others to refrain from the regrettable conduct.

Whether an obligation is diminished or eliminated may depend on the severity of the risks and costs associated with unilateral moral restraint. No doubt, this formulation is still imprecise and open to debate. However, it is sufficient to serve the purpose for which it is intended.

\section{The Character of Our Enterprise}

To be fair, what confused Strudler and may confuse others, particularly those not familiar with our prior work, is that the character of MTP differs from traditional approaches in business ethics. MTP favors a pragmatic balance between the calls of morality and prudence over the idealism of most business ethics. The kind of conditional goodwill described by MTP may seem strange and unsavory, because unilateral moral action is both more familiar and admirable to ethicists.

The development of MTP also differed from the development of most moral theories. Rather than being a view derived from first principles and tested against our highest (arm-chair) moral intuitions, it was derived from our conversations with business negotiators, lawyers, and students in negotiation classes. When these informants expressed a reluctance to be honest when they could not trust the other side to be equally honest, we formulated MTP to capture the ethics of people who consider themselves to be reasonably moral yet feel justified acting in a regrettable fashion. Rather than a finely nuanced normative dictum, we see the MTP as a building block in a larger program of pragmatic business ethics. It shows us how we might help improve practice when we cannot effectively sway people toward unilateral moral commitment with philosophical arguments. It points to the lever of trust.

We embarked on this course of development in order to speak effectively to business practitioners and to offer them actionable advice that they might take seriously. We believe that one important goal of business ethics as a field is to promote constructive change in business practices. This is not the only legitimate goal, but it seems essential if business ethics is to hold its own relative to other fields in business (e.g., marketing, strategy, finance, etc.). In exploring how business ethics could be most effective, our attention was brought to a disconnect between some of the moral theories that ethicists were relying on in their research and what we were hearing in conversations with practitioners. We began to wonder if F. H. Bradley might not be right in his observation about the limits of theoretical ethics:

The man who can give moral advice is the man of experience, who, from his own knowledge and by sympathy, can transport himself into another's case; who knows the heart and sees through moral illusion; and the man of mere theory is in the practical sphere a useless and dangerous pedant. (Bradley, 1927 p. 226)

Bradley did not convince us to give up the search for theory, but he encouraged us to try to develop a more sympathetic understanding of actual practices. We took advice from Annette Baier's interpretation of David Hume's perspective on applied ethics "The brief for 'applied' philosophy which we get from Hume, then, is one that directs the philosopher to learn from the non-philosophers before presuming to advise them." Following Baier, we sought "to become less of an intellectual judge and more or an apprentice participant" (p. 39).

The MTP was an early attempt to articulate what we were hearing in our relationships with practitioners. Nothing that we have seen or heard in the past few years has undermined our confidence in the spirit of MTP and its value as a working hypothesis. We could spend more time trying to refine it, but we think this would be less valuable than spending the same time helping practitioners use the core ideas of this theory to devise practical solutions to moral problems. This theory allows us to speak to practitioners in a way that is both sympathetic and constructive. It is neither an apology for current practices nor a brief for extreme criticism. By helping business people find ways to build trust and lower the risks and costs of moral restraint, we thought we could have a greater positive impact on business practice than we could have debating the finer points of the morality of deception in negotiation.

Admittedly, even with the modifications suggested here, the MTP might not hold up to empirical research. As both Strudler and Boatright (1992) point out, MTP is an empirical matter and could be subject to standard systematic study, refinement, and perhaps refutation. Though we have not amassed systematic evidence for the MTP, we openly welcome empirical research. As we stated in our first paper, "Many questions remain about the Mutual Trust Perspective. The theory clearly needs to be fleshed-out in more detail. Empirical work is needed to provide a better understanding of how this perspective is 
reflected in practical decision making. We need to find out whether people normally think and act like moral pragmatists, as we characterize them." (1991, p. 160) Some potentially relevant work is being done on this score (see Tenbrunsel, 1995), but the results that we have seen so far are not conclusive with regard to the role of trust in justifying deception in negotiation. Even acknowledging that point, we see little harm done by focusing our work on building trust in business negotiations.

This kind of constructive, practitioner-oriented approach to business ethics is relatively new. We do not claim to have fully worked out its shape and character, and we welcome like-minded souls to push this type of work further. What we envision is an interdisciplinary approach that would weave philosophy, morality, social science, common sense, and business experience together to provide practitioners with guidance that speaks directly to them and that provides practical advice. This new research program would focus more on strategies for constructive action and less on judgmental evaluation. This approach would take seriously how business people think. The key questions are: How do we learn from and work with business people who are not likely to be persuaded by philosophical arguments, who may well lose patience with the qualifications and abstractions that form a central part of our disciplinary heritage? How do we provide constructive advice rather than simply condemning or excusing their actions? Moral theory can help point the direction for improvement, but it alone cannot provide the road map or strategy for getting there.

\section{Concluding Comments}

To return to the central point of this paper, the core of our argument regarding deception in negotiation is this:

1. Contrary to Strudler's thesis, the world would generally be better off with less deception in negotiation, including deception about settlement preferences.

2. Philosophical arguments about the moral value of honesty are not likely to persuade many practitioners to change their behavior, and arguments that justify or excuse deception may reinforce a regrettable practice.

3. The practice of deception in negotiation rests, in large part, on the absence of social mechanisms to secure mutual trust and on perceived risks and costs associated with unilateral moral restraint.

4. The most promising avenue for reducing undesirable deception is to give business people the conceptual and practical tools for building trust and securing their interests.

The bulk of our second paper (1993) was devoted to presenting those concepts and tools, using the literature of game theory and negotiation to develop our points. We hope that interested readers will read our earlier work and decide for themselves whether Strudler's approach to the problem of deception is superior.

Harvard University

University of Maryland 
${ }^{1}$ We are deeply grateful for the suggestions and advice provided by Jaan Elias.

\section{Bibliography}

Annette Baier: 1985. "Doing Without Moral Theory?" Postures of the Mind: Essays on Mind and Morals (Metheun, London), pp. 228-245. (Also reprinted in Clarke and Simpson, 1989, pp. 29-48, page references in the text are to the reprinted version.)

John R. Boatright: 1992. "Morality in Practice: Dees, Cramton, and Brier Rabbit," Business Ethics Quarterly, vol. 2 no. 1, pp. 63-73.

F. H. Bradley: 1927. Ethical Studies (Oxford University Press, Oxford).

Albert Carr: 1968. "Is Business Bluffing Ethical?" Harvard Business Review, vol. 46 no. 1 (Jan./Feb.), pp. 143-152.

Stanley G. Clarke and Evan Simpson (eds.): 1989. Anti-Theory in Ethics and Moral Conservatism (State University of New York Press, Albany).

Peter C. Cramton and J. Gregory Dees: 1993. "Promoting Honesty in Negotiation: An Exercise in Practical Ethics," Business Ethics Quarterly, vol. 3 no. 4, pp. 359-394.

J. Gregory Dees and Peter C. Cramton: 1991. "Shrewd Bargaining on the Moral Frontier: Toward a Theory of Morality in Practice," Business Ethics Quarterly, vol. 1 no. 2, pp. 135-167.

Kevin Gibson: 1994. "Harmony, Hobbes and Rational Negotiation: A Reply to Dees and Cramton," Business Ethics Quarterly, vol. 4 no. 3, pp. 373-381.

John Kennan and Robert Wilson: 1993. "Bargaining with Private Information," Journal of Economic Literature, vol. 31 no. 1, pp. 45-104.

Howard Raiffa: 1982. The Art and Science of Negotiation: How to Resolve Conflicts and Get the Best Out of Bargaining, (Harvard University Press, Cambridge).

Alan Strudler: 1995. "On the Ethics of Deception in Negotiation," Business Ethics Quarterly, forthcoming (same issue), references are to the original manuscript.

Anne Tenbrunsel: 1995. Justifying Unethical Behavior: The Role of Expectations of Others' Behavior and Uncertainty, doctoral dissertation, Kellogg Graduate School of Management, Department of Organizational Behavior, Northwestern University. 